\title{
POLA PEMANFAATAN DAN PEMASARAN NIBUNG DI SEKITAR KAWASAN TAMAN NASIONAL SEMBILANG PROVINSI SUMATERA SELATAN
}

\author{
(Usage and Marketing Pattern of Nibung \\ in the Area around National Park of Sembilang, Province of South Sumatera) \\ Ari Nurlia, Hengki Siahaan dan/and A.H. Lukman \\ Balai Penelitian Kehutanan Palembang \\ Jl. Kol. H. Burlian Km. 6,5 Puntikayu Palembang \\ Telp./Fax. 0711-414864
}

Naskah masuk : 1 Februari 2013; Naskah diterima : 15 November 2013

\begin{abstract}
ABSTRACK
Nibung (Oncosperma tigillarium (Jack) Ridl) is a kind of Palmae family that scatter in group and growth in clump at low tide peat ecosystem. In South Sumatera, Nibung scatter at estuary of Sembilang river, Benawang river and Alang Gantang island. Nibung is a main commodity for people living in tidal areas. Eksploitation nibung by people is not accompanied by cultivation activities in nature make population decreases every year. This research was aimed to describe the usage and marketing status of nibung in the around National Park of Sembilang. Research was conducted by survey method and analize quantitatively and qualitatively. Result showed that nibung is used as material to construct house, bridge, and facility for fishering activity like kilung, bagan (fishing pole), and toguk that need 16,325 nibung pole each year. Nibung usage is based on its length that divide into three groups of $\leq 12$ metre, 12-15 metre, and $\geq 15$ metre. Marketing of nibung is very simple that involved two main actor, they are main user and penibung (a group to search and exploit nibung).
\end{abstract}

Keyword: Nibung, usage, and marketing

\begin{abstract}
ABSTRAK
Nibung (Oncosperma tigillarium (Jack) Ridl) adalah sejenis Palmae yang tumbuh berkelompok dan berumpun pada ekosistem rawa pasang surut. Di Sumatera Selatan sebaran nibung terdapat di sekitar Taman Nasional Sembilang, yaitu di hilir Sungai Sembilang, Sungai Benawang dan Pulau Alang Gantang. Nibung merupakan komoditi utama bagi masyarakat yang tinggal di daerah pasang surut. Pemanfaatan nibung oleh masyarakat tidak disertai dengan kegiatan pembudidayaan membuat keberadaan nibung di alam semakin berkurang setiap tahunnya. Penelitian ini bertujuan untuk menjelaskan status pemanfaatan dan pemasaran nibung di masyarakat. Penelitian dilakukan dengan menggunakan metode survei dan dianalisis secara kuantitatif dan kualitatif. Hasil penelitian mengungkapkan bahwa nibung dimanfaatkan sebagai bahan pembuatan rumah, jembatan dan sarana penangkapan ikan seperti kilung, bagan dan toguk dengan kebutuhan mencapai 16.325 batang/tahun. Nibung dipasarkan berdasarkan pada panjang batangnya yang dibagi menjadi tiga kelompok, yaitu kelompok satu dengan panjang $\leq 12$ meter, kelompok dua dengan panjang antara 12-15 meter dan kelompok tiga dengan panjang $>15$ meter. Pemasaran nibung sangat sederhana dimana hanya terdapat dua pelaku pemasaran yaitu kelompok pemanfaat utama dan penibung.
\end{abstract}

Kata kunci: Nibung, pemanfaatan, pemasaran

\section{PENDAHULUAN}

\section{A. Latar Belakang}

Nibung (Oncosperma tigillarium) merupakan sejenis palmae yang umumnya tumbuh secara alami dan berumpun seperti bambu. Nibung merupakan Hasil Hutan Bukan Kayu (HHBK) termasuk palem yang dimanfaatkan batangnya (Per- menhut No P.35, 2007). Secara alami, nibung tersebar di Srilangka, Philipina, Thailand, Indonesia, dan Vietnam. Di Sumatera Selatan tumbuhan nibung tersebar pada daerah ekoton, salah satunya di Taman Nasional Sembilang dan sekitarnya (Sahwalita dan Baktiawan, 2010).

Pohon nibung telah lama dimanfaatkan oleh masyarakat terutama oleh nelayan. Hampir semua bagian nibung dapat dimanfaatkan mulai 
dari batang, buah hingga daunnya. Batang nibung digunakan sebagai bahan bangunan dan daunnya digunakan untuk membuat atap rumah dan anyaman keranjang. Bunga pohon nibung digunakan untuk mengharumkan beras, sedangkan umbut dan kuncup bunga dapat dibuat sayur. Buah nibung dapat dipakai sebagai teman makan sirih pengganti pinang dan durinya yang disebut "pating" dapat dipakai sebagai paku bangunan sesaji dalam upacara adat. Batang maupun daun pohon nibung memiliki daya tahan yang lama dan tidak mudah lapuk meskipun terendam dalam air payau. Bahkan salah satu temuan arkeolog menyebutkan bahwa batang Nibung telah dipergunakan sebagai bahan bangunan di lahan gambut oleh masyarakat Jambi sejak abad kesebelas (Alamendah, 2011). Menurut Rangkuti (2008) Para arkeolog juga menemukan batangbatang pohon nibung di antara sebaran artefak. Selain batang, rebusan akar nibung dapat digunakan sebagai obat penurun panas (Heyne, 2008).

Di Wilayah Sungsang dan Tanjung Lago, nibung merupakan komoditi utama bagi masyarakat. Mereka memanfaatkan nibung untuk keperluan perikanan seperti renovasi bagan, kilung dan sarip. Di daerah pasang surut, nibung diperjual belikan sebagai bahan bangunan dan tiang rumah.

Saat ini ketersediaan nibung di alam cenderung semakin berkurang akibat aktivitas pemanfaatan nibung dalam jumlah besar tanpa adanya kegiatan pembudidayaan. Di beberapa hulu sungai di wilayah Taman Nasional Sembilang, tegakan nibung di alam bahkan hanya terlihat sisa-sisa tunggaknya saja (BTNS, 2008). Dengan semakin berkurangnya nibung di alam dikhawatirkan eksploitasi nibung akan mulai memasuki kawasan hutan.

Beberapa penelitian mengenai nibung telah dilakukan, diantaranya penelitian yang dilakukan oleh Siahaan dan Lukman (2011) mengenai ekologi dan sebaran nibung, Sahwalita dan Baktiawan (2010) mengenai alternatif budidaya nibung di areal Hutan Tanaman Rakyat, dan Lukman et al., (2010) mengenai pengembangan nibung sebagai sumber pangan dan kayu pertukangan. Namun, penelitian-penelitian tersebut hanya mengkaji pada aspek silvikulturnya. Oleh karena itu perlu adanya suatu penelitian yang mengkaji aspek sosial ekonomi untuk mengetahui status nibung di masyarakat agar dapat digunakan sebagai dasar untuk pengembangan nibung di masyarakat.

\section{B. Tujuan Penelitian}

Tujuan penelitian ini adalah untuk menguraikan dan menjelaskan pemanfaatan, tingkat kebutuhan dan pemasaran nibung di masyarakat.

\section{METODE PENELITIAN}

\section{A. Waktu dan Lokasi Penelitian}

Penelitian dilaksanakan pada bulan Juni sampai dengan Oktober 2011. Lokasi dipilih secara sengaja (purposive) berdasarkan infor-masi awal yang diperoleh dari kegiatan yang dilakukan oleh Taman Nasional Sembilang mengenai identifikasi nibung di sekitar Taman Nasional Sembilang. Taman Nasional Sembilang merupakan kawasan konservasi terluas di pesisir timur Pulau Sumatera yang sebagian besar terdiri dari hutan mangrove, dialiri oleh lebih dari 30 sungai dan bermuara di Selat Bangka dan Laut Cina Selatan (SPTN II, 2009). Berdasarkan informasi tersebut, lokasi penelitian terpilih adalah Wilayah Sungsang dan Desa Tanjung Lago.

\section{B. Metode Pengumpulan dan Analisis Data}

Penelitian ini merupakan penelitian survei dengan metode dasar deskriptif analisis. Pengumpulan data, baik berupa data primer maupun data sekunder dilakukan melalui studi awal (pra survei) dan survei lapangan. Pedoman wawancara digunakan sebagai alat bantu pengumpulan data dan wawancara mendalam dilakukan untuk mendapatkan data yang lebih lengkap dan akurat. Data primer didapat berdasarkan responden yang terpilih secara sengaja (purposive) meng-ikuti rantai pemanfaatan nibung.

Responden terpilih merupakan responden yang mewakili pemanfaatan nibung dari hulu ke hilir yaitu para aktor atau pelaku aliran pemasaran nibung yang terdiri dari 7 (tujuh) kelompok pemanfaat nibung dan 3 (tiga) kelompok penibung yang berjumlah masing-masing sepuluh responden setiap kelompoknya.

Tingkat eksploitasi dan kerusakan tegakan nibung dilihat dari hasil pengukuran potensi. Pengukuran potensi tidak dilakukan di seluruh wilayah eksploitasi nibung dikarenakan keterbatasan waktu dan sulitnya medan. Pengukuran dilakukan dengan membuat petak-petak pengamatan berukuran $20 \mathrm{~m} \times 20 \mathrm{~m}$ pada lokasi sebaran di Sekitar Taman Nasional Sembilang, yaitu di Sungai Simpang Tawar, Sungai Capo Besar dan Pulau Alang Gantang. Pada masing-masing petak 
dilakukan pengukuran terhadap jumlah rumpun, jumlah pohon, jumlah tunggak, jumlah pohon mati, jumlah anakan, dan diameter tegakan.

Pemanfaatan dan kebutuhan nibung di analisis dengan menggunakan analisis sosial dalam bentuk analisis tabulasi dan deskriptif. Analisis tabulasi dilakukan dengan mengelompokkan data-data menjadi beberapa kelompok sesuai dengan tujuan penelitian. Analisis deskriptif dilakukan untuk menganalisis dan menjelaskan data penelitian yang bersifat kualitatif.

Aliran Pemasaran di analisis dengan menggunakan rantai nilai (Value chain). Rantai nilai ini berasal dari aktifitas-aktifitas yang dilakukan, mulai dari bahan baku sampai ke tangan konsumen, termasuk juga pelayanan purna jual (Shank dan Govindarajan, 1992). Kaplinsky dan Morris (2000) mendefinisikan rantai nilai sebagai gambaran kegiatan yang diperlukan untuk menghasilkan suatu barang dan jasa. Di dalam rantai nilai ini akan melibatkan pelaku yang masing-masing pelaku akan memberikan pertambahan nilai dari barang dan jasa tersebut atau dengan kata lain setiap pelaku akan mendapatkan marjin keuntungan atas pertambahan nilai tersebut, yang disebut nilai tambah (Martin, et al., 2010). Nilai tambah adalah selisih antara pendapatan yang diperoleh dengan biaya yang dikeluarkan untuk memperoleh barang dan jasa.

\section{HASIL DAN PEMBAHASAN}

\section{A. Nibung dan Masyarakat}

Bagi masyarakat nelayan khususnya yang tinggal di daerah pasang surut, nibung merupakan bagian yang tidak terpisahkan dari kehidupan mereka. Tanpa nibung masyarakat tidak dapat memenuhi kebutuhan hidupnya dalam mencari ikan. Besarnya kebutuhan nibung menyebabkan sebagian masyarakat memilih untuk berprofesi sebagai "penibung" yaitu kelompok orang yang mencari nibung di alam. Nibung di alam yang cenderung mengelompok memudahkan penibung untuk melakukan eksploitasi dan mengangkutnya dalam bentuk gelondongan ke lokasi pemanfaatan (Gambar 1).

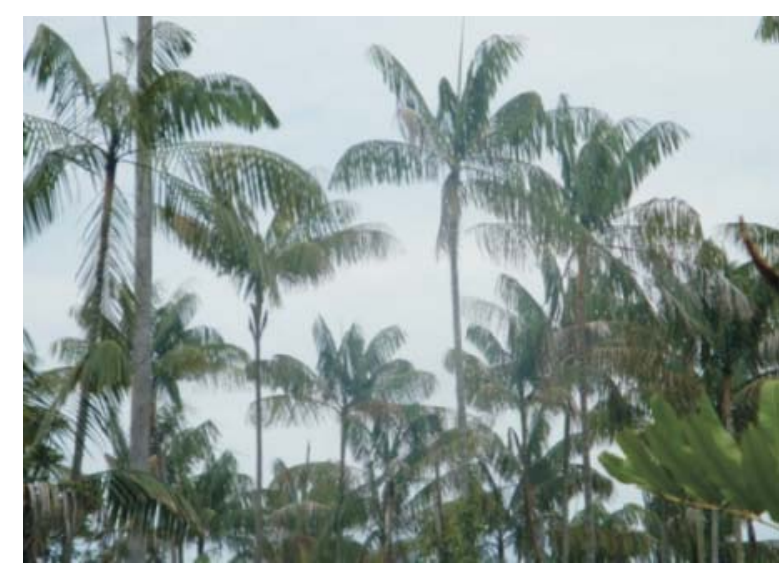

(a)

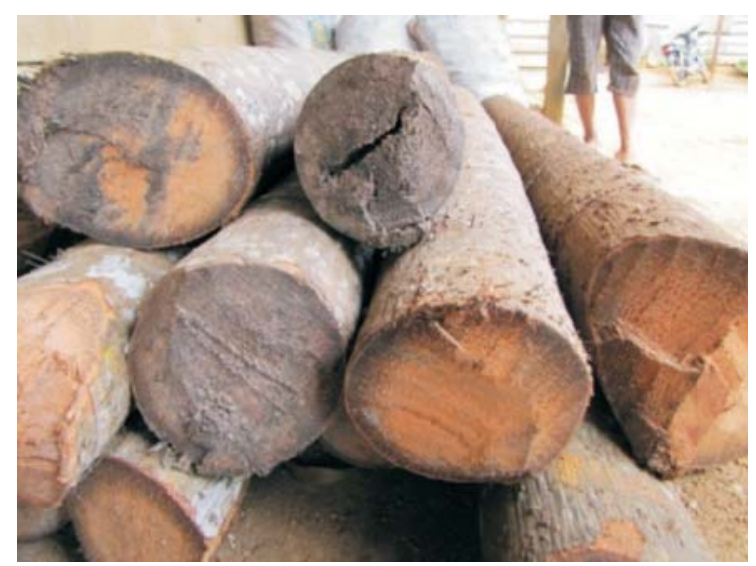

(b)

Gambar(Figure)1. Tegakan nibung di Taman Nasional Sembilang (Nibung stand in National Park of Sembilang) (a) dan batang nibung yang siap digunakan (Nibung log that ready to used) (b)

Sebagian besar penibung memperoleh nibung dari Sungai Sembilang dan Sungai Benawang yang merupakan daerah sekitar kawasan Taman Nasional Sembilang (Gambar 2). Hal ini sesuai dengan hasil penelitian yang telah dilakukan Lukman et al., (2010) dimana sebaran alami nibung di Kabupaten Banyuasin terdapat di sekitar kawasan Taman Nasional Sembilang (Gambar 3). 


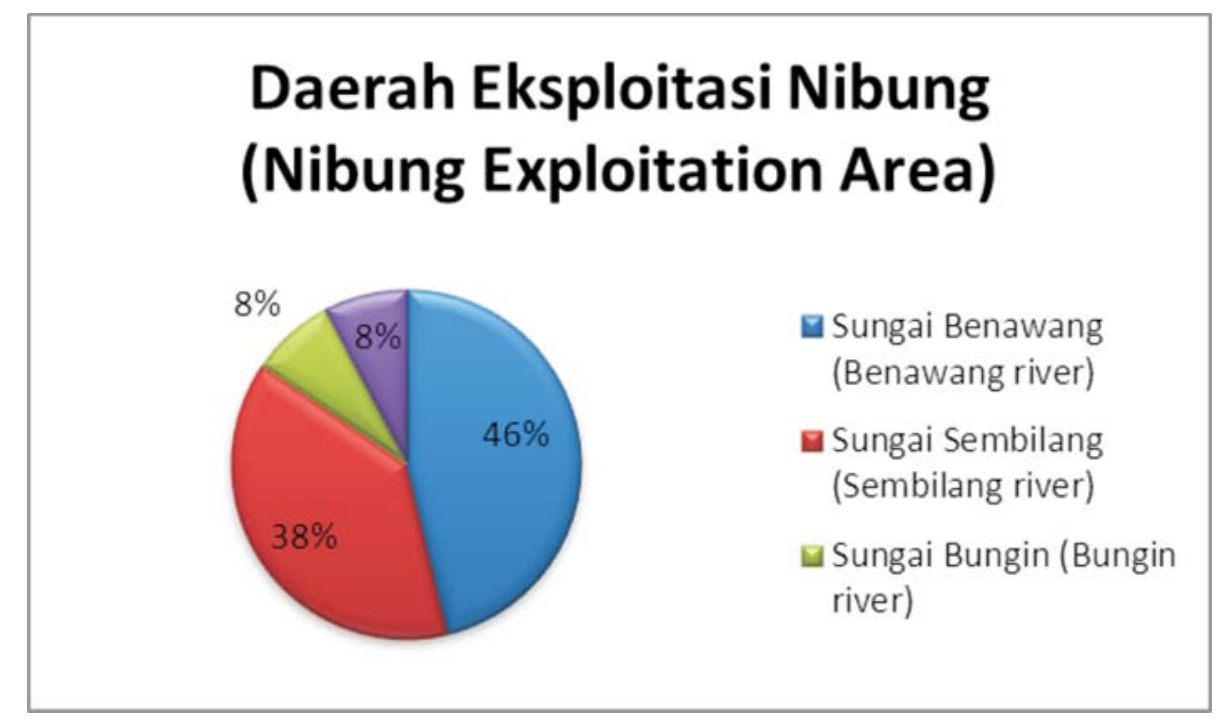

Gambar(Figure) 2. Daerah exploitasi nibung di sekitar Taman Nasional Sembilang (Exploitation area of nibung around National Park of Sembilang)
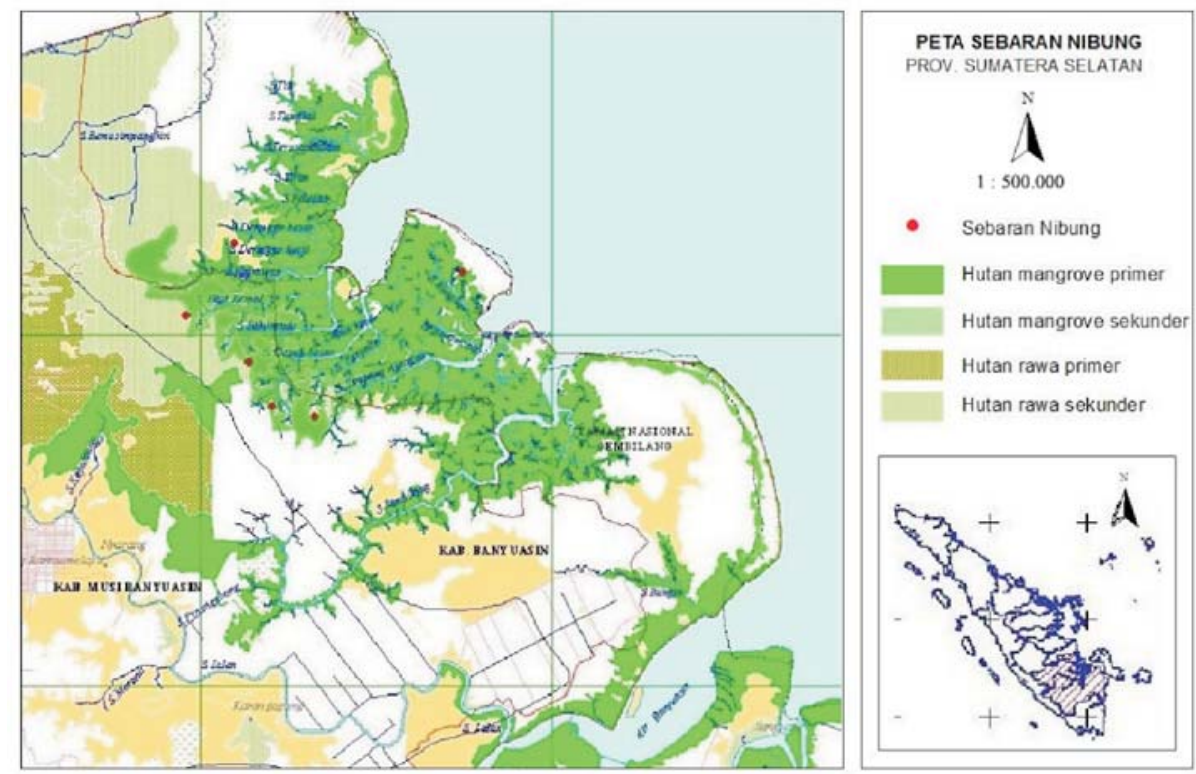

Gambar(Figure)3. Peta sebaran alami nibung di Kabupaten Banyuasin, Sumatera Selatan (Ature scatter map of nibung in Banyuasin Regency, South Sumatera) (Sumber (Source): Lukman etal., 2010)

Berdasarkan pada pengukuran potensi yang dilakukan Lukman et al., (2009) pada sebaran nibung di Sekitar Taman Nasional, diketahui potensi nibung disekitar Kawasan Taman Nasional sebagaimana terdapat pada Tabel 1. Pengukuran potensi dilakukan dibeberapa wilayah untuk mengetahui tingkat eksploitasi dan kerusakan tegakan nibung. 
Tabel (Table) 1. Potensi dan permudaan nibung di sekitar Kawasan Taman Nasional Sembilang (Potency and regeneration of nibung around National Park of Sembilang)

\begin{tabular}{|c|c|c|c|c|c|c|c|}
\hline No & $\begin{array}{l}\text { Daerah } \\
\text { (Region) }\end{array}$ & $\begin{array}{l}\text { Jumlah } \\
\text { rumpun } \\
\text { (Number of } \\
\text { clamps)/ha }\end{array}$ & $\begin{array}{l}\text { Jumlah } \\
\text { pohon } \\
(\text { Number of } \\
\text { trees }) / \text { ha }\end{array}$ & $\begin{array}{c}\text { Jumlah } \\
\text { tunggak } \\
\text { (Number of } \\
\text { tumps)/ha }\end{array}$ & $\begin{array}{c}\text { Jumlah } \\
\text { pohon mati } \\
\text { (Number of } \\
\text { dead } \\
\text { trees)/ha } \\
\end{array}$ & $\begin{array}{l}\text { Jumlah } \\
\text { anakan } \\
\text { (Number of } \\
\text { seedling)/ha }\end{array}$ & $\begin{array}{c}\text { Rerata } \\
\text { diameter } \\
\text { (Average } \\
\text { diameters) } \\
(\mathrm{cm}) \\
\end{array}$ \\
\hline 1 & $\begin{array}{l}\text { Sungai } \\
\text { Simpang } \\
\text { Tawar } \\
\text { (Simpang } \\
\text { Tawar river ) }\end{array}$ & 425 & 1.413 & 1.749 & 837 & 2.262 & 9,3 \\
\hline 2 & $\begin{array}{l}\text { Sungai Capo } \\
\text { Besar } \\
\text { (Capo besar } \\
\text { river) }\end{array}$ & 235 & 732 & 889 & 387 & 1.847 & 9,0 \\
\hline 3 & $\begin{array}{l}\text { Pulau Alang } \\
\text { Gantang } \\
\text { (Alang } \\
\text { Gantang } \\
\text { island) }\end{array}$ & 333 & 2.490 & 0 & 366 & 2.328 & 9,4 \\
\hline
\end{tabular}

Dari tabel diketahui hampir semua tegakan nibung telah mengalami eksploitasi oleh para penibung, bahkan telah terjadi over eksploitasi yang menyisakan tunggak, tegakan rusak, serta tegakan yang masih muda sehingga mengakibatkan terjadinya kerusakan habitat yang cukup serius pada kawasan ini. Habitat nibung yang relatif terjaga adalah sebaran nibung di Pulau Alang Gantang dimana belum terjadi eksploitasi nibung yang terlihat dari tidak adanya tunggak yang ditemukan di wilayah ini. Habitat Pulau Alang Gantang relatif terjaga karena sulit dijangkau dan terawasi oleh Balai Taman Nasional Sembilang (Siahaan dan Lukman, 2011).

Saat ini telah dicoba beberapa jenis kayu seperti kayu gelam, jangkang, nyiri dan kayu bedado untuk menggantikan nibung. Namun, kayu-kayu tersebut tidak memiliki kekuatan dan keawetan seperti halnya batang nibung. Dalam air sungai maupun laut, batang nibung dapat bertahan hingga 2 (dua) tahun sementara kayu lainnya hanya dapat bertahan kurang dari satu tahun.

Kesulitan dalam mencari nibung dirasakan masyarakat sejak tahun 2000. Hal ini terjadi karena tingginya kebutuhan nibung tanpa disertai dengan kegiatan budidaya, sehingga masyarakat hanya memanfaatkan nibung yang ada di alam. Pada dasarnya seluruh responden bersedia untuk melakukan budidaya nibung, namun hal ini sulit dilakukan karena terbatasnya lahan yang dimiliki dan kurangnya pengetahuan mengenai teknik budidaya nibung. Menurut kajian dari Balai Taman Nasional Sembilang (2008), masyarakat pada dasarnya memahami pentingnya pelestarian nibung melalui upaya pembudidayaan secara exsitu (di luar habitat aslinya), namun partisipasi nyata masyarakat dalam jangka pendek belum terlihat dikarenakan mereka belum melihat bukti dan keberhasilaan budidaya maupun penanaman nibung.

Pada awalnya masyarakat hanya memanfaatkan nibung yang berada di daerah ekoton, yaitu daerah peralihan antara ekosistem bakau dengan rawa yang biasanya berada di hulu sungai. Ketersediaan nibung yang semakin terbatas membuat sebagian masyarakat mulai melakukan perambahan pada kawasan Taman Nasional Sembilang (TNS). Perambahan dilakukan karena Taman Nasional Sembilang merupakan lokasi sebaran nibung terdekat yang dapat dijangkau. Selain di Taman Nasional sembilang, mereka harus mencari nibung pada lokasi yang sangat jauh hingga Pulau Bangka, dengan konsekuensi biaya yang lebih besar.

\section{B. Pemanfaatan Nibung oleh Masyarakat}

Nibung merupakan komoditi utama yang sangat penting bagi masyarakat nelayan di daerah Sungsang yang hingga kini belum ditemukan 
substitusinya. Kesulitan mencari nibung mengakibatkan sebagian masyarakat yang awalnya berprofesi sebagai nelayan beralih profesi menjadi pedagang atau tukang becak.

Pemanfaatan nibung telah dilakukan secara turun-temurun. Di pemukiman, batang nibung dimanfaatkan sebagai tiang pada rumah panggung, galar (lantai), dan jerambah (jembatan), bahkan ada yang memanfaatkan batang nibung sebagai pipa untuk saluran air.

Di laut atau sungai, batang nibung digunakan untuk membuat bagan, kilung dan toguk (Gambar 4). Bagan adalah sejenis rumah panggung yang dibuat di sungai atau laut yang digunakan sebagai tempat peristirahatan dan persiapan sebelum menangkap ikan. Kilung adalah sebuah bagan yang dibuat di tengah laut dengan sarip di kanan kirinya. Sarip merupakan tiang-tiang yang ditanam dikanan kiri bagan yang berfungsi untuk mengarahkan ikan masuk ke dalam kilung untuk selanjutnya dijaring secara periodik. Sedangkan toguk adalah suatu alat yang digunakan untuk mengambil ikan oleh nelayan yang berbentuk seperti gapura-gapura kecil (awangan) yang membentang dari tepian hingga tengah sungai.
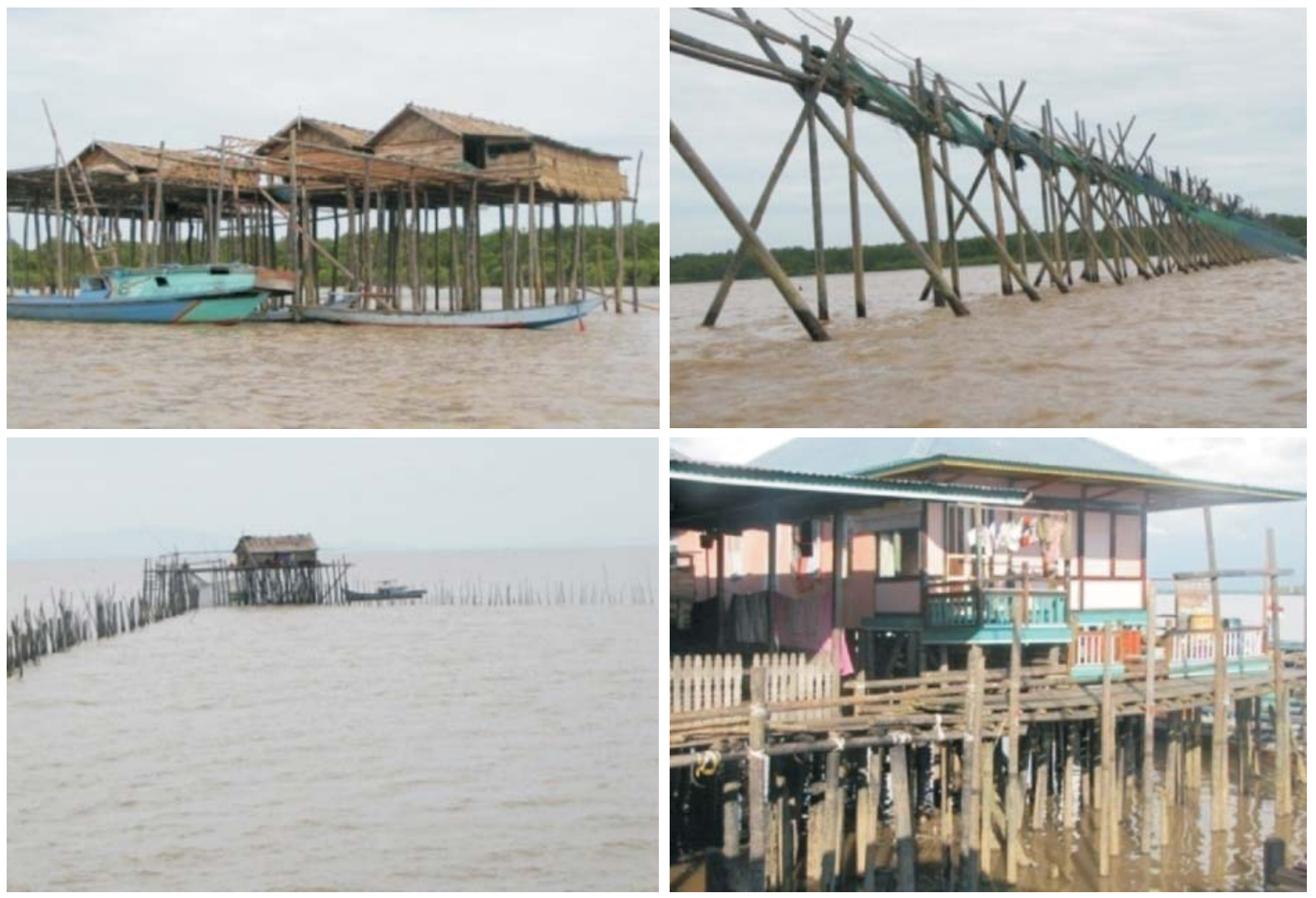

Gambar (Figure) 4. Bagan (bagan) (a), toguk (toguk) (b), kilung (kilung) (c), dan rumah (house) (d)

Berdasarkan tahap pemakaiannya, kebutuhan masyarakat terhadap nibung dapat dibedakan atas dua tahap, yaitu kebutuhan awal untuk pembangunan sarana perikanan dan kebutuhan untuk pemeliharaan. Pemeliharaan diperlukan karena umur pemakaian nibung biasanya hanya berkisar satu hingga dua tahun dan penggantian batang yang telah rusak perlu dilakukan secara rutin setiap tahunnya. Kebutuhan batang nibung untuk kegiatan pembangunan dan pemeliharaan sarana penangkapan ikan oleh masyarakat nelayan dapat dihitung berdasarkan pendekatan jumlah bangunan yang dimiliki masyarakat (Tabel 2). 
Tabel (Table) 2. Analisis kebutuhan nibung untuk pembuatan dan pemeliharaan sarana penangkapan ikan di daerah Sungsang, Sumatera Selatan (Nibung demand analysis for fishing equipment construction and maintenance in Sungsang region, South Sumatera)

\begin{tabular}{|c|c|c|c|c|c|c|}
\hline \multirow[b]{2}{*}{ No } & \multicolumn{2}{|c|}{$\begin{array}{c}\text { Sarana } \\
\text { (Fishingment equipment) }\end{array}$} & \multicolumn{4}{|c|}{$\begin{array}{c}\text { Kebutuhan nibung (Nibung needs) } \\
\text { (btg (stem) }\end{array}$} \\
\hline & $\begin{array}{c}\text { Jenis } \\
\text { (Kind of } \\
\text { equipment) }\end{array}$ & $\begin{array}{c}\text { Jumlah } \\
\text { (Number) }\end{array}$ & $\begin{array}{c}\text { Pembuatan/ } \\
\text { Unit } \\
\text { (Contruction } \\
\text { needs/unit) }\end{array}$ & $\begin{array}{c}\text { Jumlah } \\
\text { Pembuatan } \\
\quad \text { (Total } \\
\text { contruction) }\end{array}$ & $\begin{array}{l}\text { Pemeliharaan/ } \\
\text { unit/tahun } \\
\text { (Maintenance } \\
\text { /unit/year) }\end{array}$ & $\begin{array}{c}\text { Pemeliharaan/ } \\
\text { tahun } \\
\text { (Total } \\
\text { maintenance) }\end{array}$ \\
\hline 1. & $\begin{array}{l}\text { Rumah } \\
\text { (House) }\end{array}$ & 250 & 100 & 25.000 & 5 & 1.250 \\
\hline 2. & $\begin{array}{l}\text { Bagan } \\
\text { (Bagan) }\end{array}$ & 48 & 200 & 9.600 & 15 & 675 \\
\hline 3. & $\begin{array}{l}\text { Kilung } \\
\text { (Kilung) }\end{array}$ & 31 & 1.000 & 31.000 & 400 & 12.400 \\
\hline 4. & $\begin{array}{l}\text { Toguk } \\
(\text { Toguk })\end{array}$ & 2.000 & 100 & 200.000 & 1 & 2.000 \\
\hline \multicolumn{4}{|c|}{$\begin{array}{l}\text { Total kebutuhan nibung per tahun } \\
\text { (Total of nibung demand per year) }\end{array}$} & 265.600 & & 16.325 \\
\hline
\end{tabular}

Pemanfaatan nibung lebih banyak digunakan untuk pemeliharaan, terutama untuk pemeliharaan rumah, kilung dan bagan. Pembuatan sarana baru sudah tidak memungkinkan lagi karena banyaknya nibung yang dibutuhkan sementara ketersediaan nibung di alam sudah sangat terbatas. Misalnya untuk pembangunan kilung yang memerlukan nibung hingga 1.000 batang/unit. Sehingga sarana baru yang memungkinkan untuk di bangun adalah toguk yang setiap unitnya hanya memerlukan 100 batang nibung.
Dalam penggunaannya, masyarakat menggunakan batang nibung berdasarkan ukuran depa, dimana satu depa setara dengan 1,7 meter. Berdasarkan panjangnya, batang nibung dikelompokkan menjadi 3 (tiga) kelompok. Kelompok 1 (satu) dengan panjang $\leq 12$ meter ( 7 depa) digunakan sebagai tiang-tiang penyangga rumah panggung, lantai dan jembatan. Kelompok 2 (dua) dengan panjang antara 12-15 meter (7-9 depa) digunakan sebagai sarip pada kilung dan Kelompok 3 (tiga) dengan panjang $\geq 15$ meter $(9$ depa) digunakan untuk membuat bagan.

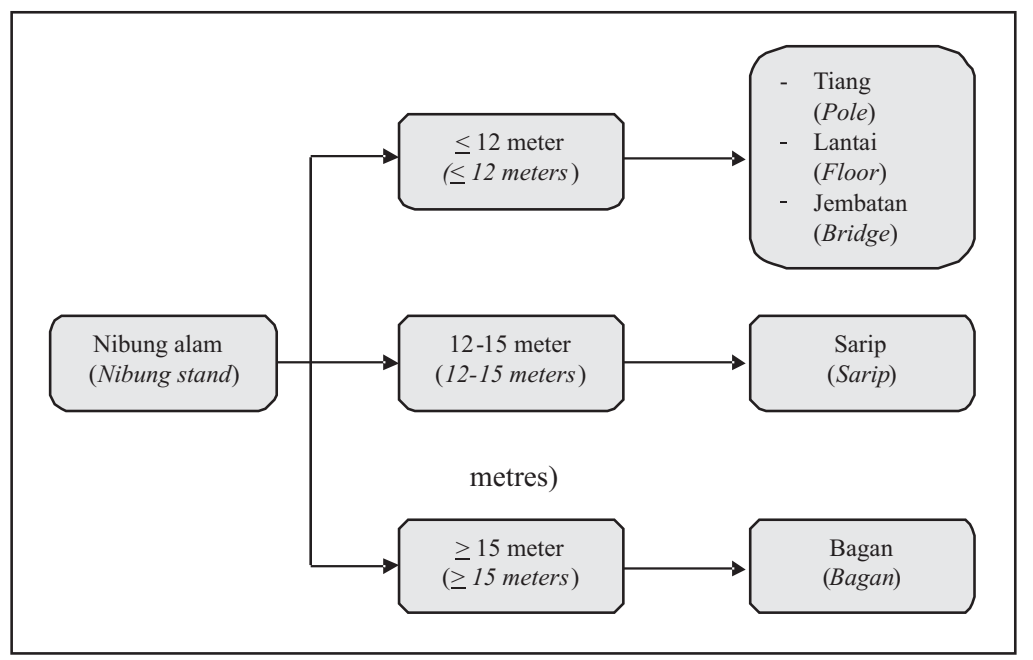

Gambar (Figure) 5. Varian Pola Pemanfaatan Nibung (Nibung usage pattern variation) 


\section{Pemasaran Nibung}

Pemasaran adalah suatu proses sosial dan manajemen, dimana individu-individu atau kelompok dapat memenuhi kebutuhan dan keinginannya melalui pembuatan dan pertukaran suatu produk dan uang dengan individu-individu atau kelompok lainnya (Kotler, 2002). Pemasaran batang nibung berbeda dengan pemasaran kayukayu kehutanan lain pada umumnya. Mengacu pada Limbong dan Sitorus (1987), saluran pemasaran batang nibung tergolong pada saluran non tingkat (zero level channel) dimana produsen langsung menjual produknya ke konsumen. Batang nibung tidak dipasarkan secara bebas tetapi berdasarkan pesanan dan hanya dilakukan oleh orang-orang tertentu yang memiliki modal besar yaitu para pemilik kilung yang merupakan pemanfaat utama nibung. Sementara untuk pemanfaat lainnya seperti pemilik toguk dan untuk perumahan masyarakat yang hanya membutuhkan batang nibung dalam jumlah sedikit, umumnya hanya menginduk kepada para pemilik kilung. Untuk mendapatkan batang nibung, pemilik kilung atau bagan memesan langsung kepada para penibung (Gambar 6).

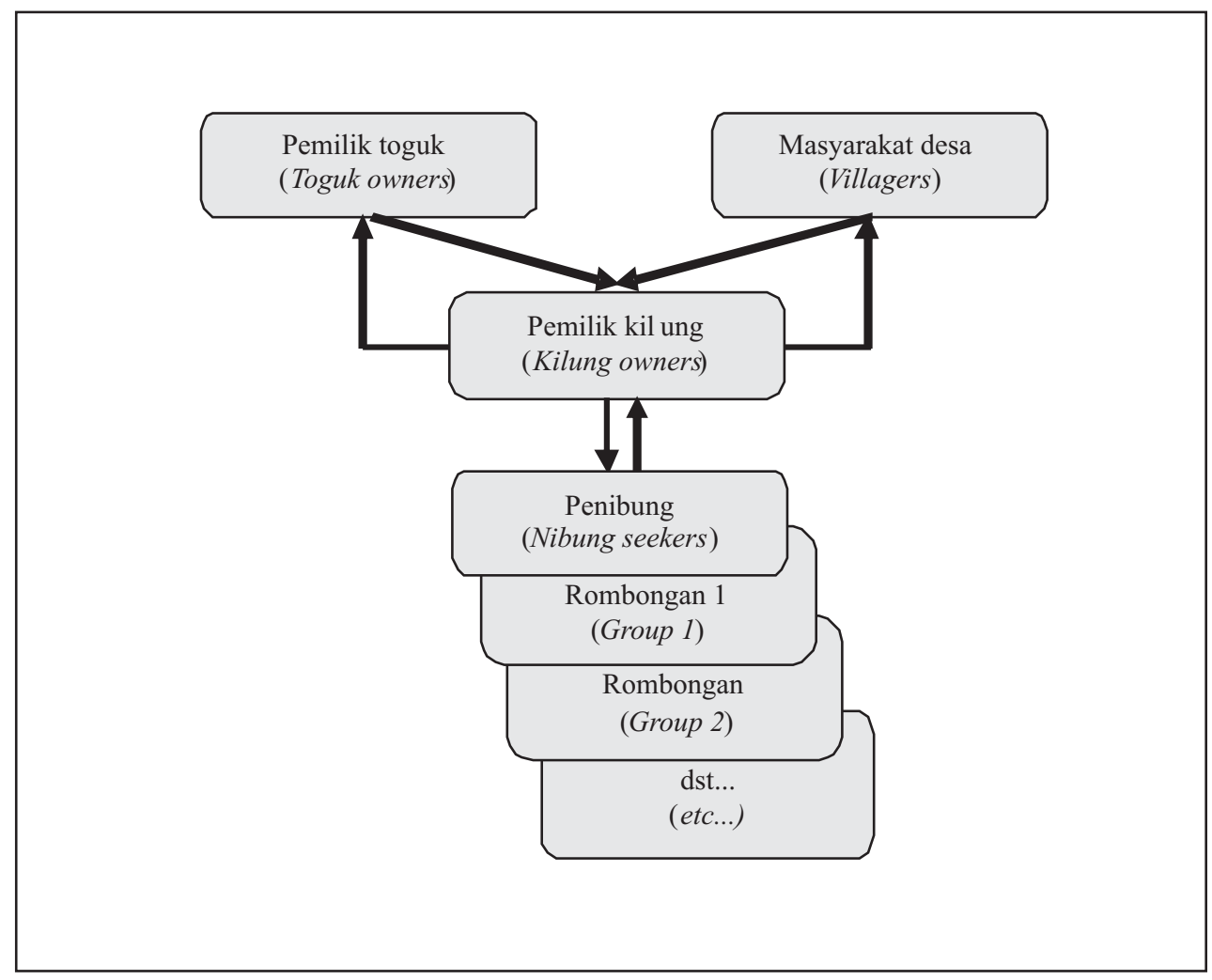

Gambar (Figure) 6. Aliran pemasaran nibung (Nibung marketing flow scheme)

Pada pemasaran nibung, hanya terdapat 2 (dua) pelaku pemasaran yaitu pemanfaat utama dan penibung. Pemanfaat utama merupakan orangorang yang memiliki modal besar yang berkepentingan langsung terhadap nibung yaitu para pemilik kilung. Pemanfaat ini merupakan pemanfaat nibung dalam jumlah besar yang mencapai 1.000 batang setiap tahunnya. Untuk pemanfaat-pemanfaat lainnya atau yang disebut pemanfaat lanjutan yang hanya membutuhkan batang nibung dalam jumlah kecil, yaitu para pemiliki toguk atau masyarakat desa yang membutuhkan nibung untuk pemeliharaan (penggantian) tiang rumah yang rusak dimana mereka mendapatkan batang nibung dari pemanfaat-pemanfaat utama.

Walaupun para pemanfaat lanjutan mendapatkan batang nibung dari pemanfaat utama, namun pemanfaat utama sebenarnya bukan pelaku utama pemasaran batang nibung. Hal ini dikarenakan pemanfaat utama hanya bersifat membantu para pemanfaat lanjutan untuk mendapatkan batang nibung karena batang nibung tidak dapat dipesan dalam jumlah sedikit melainkan dalam jumlah besar sehingga dibutuhkan modal yang besar. 
Pada pemasaran dan nilai tambah batang nibung di seluruh kelompok penggunaannya dimana kelompok 1 (satu) dengan panjang $\leq 12$ meter, kelompok 2 (dua) dengan panjang antara 12-15 meter dan kelompok 3 (tiga) dengan panjang $>15$ meter, jumlah pelaku pada rantai nilai nibung berjumlah 2 (dua) pelaku yaitu penibung dan pemanfaat utama. Pemanfaat lanjutan tidak tergolong dalam pelaku pemasaran dikarenakan tidak adanya penambahan nilai dari pemanfaat utama ke pemanfaat lanjutan. Penambahan nilai atau masukan input yang terdiri dari tenaga kerja, transportasi dan perijinan akan memberikan nilai tambah yang besar pada pemasaran nibung. Nilai nibung pada kelompok satu sampai pelaku ter- akhir sebesar Rp 40.000,-. Nilai tambah terbesar terdapat pada pemanfaat utama dengan nilai tambah sebesar $75 \%$ dan penibung dengan nilai tambah sebesar 25\%. Nilai nibung pada kelompok dua sampai pelaku terakhir sebesar Rp 60.000,dengan nilai tambah pada setiap pelaku masingmasing sebesar 50\%. Sedangkan nilai nibung pada kelompok tiga sebesar Rp 70.000,- dengan nilai tambah terbesar terdapat pada penibung dengan nilai tambah sebesar $75 \%$ dan pemanfaat utama dengan nilai tambah sebesar $25 \%$. Untuk mendapatkan gambaran yang jelas mengenai pemasaran dan nilai tambah batang nibung dapat dilihat pada Tabel 3 .

Tabel (Table) 3. Distribusi nilai tambah nibung pada setiap kelompok penggunaan (Nibung added value distribution for every usage group)

\begin{tabular}{|c|c|c|c|c|}
\hline \multirow{2}{*}{$\begin{array}{l}\text { Pelaku } \\
\text { (Subject) }\end{array}$} & \multirow{2}{*}{$\begin{array}{c}\text { Nilai output } \\
\text { (Output value ) } \\
\text { (Rp.) }\end{array}$} & \multirow{2}{*}{$\begin{array}{l}\text { Nilai input } \\
\text { (Input value ) } \\
\text { (Rp.) }\end{array}$} & \multicolumn{2}{|c|}{$\begin{array}{c}\text { Nilai tambah bersih per batang } \\
\text { bahan baku } \\
\text { (Added value/log) }\end{array}$} \\
\hline & & & Rp. & $\begin{array}{c}\% \\
(\text { Percent })\end{array}$ \\
\hline \multicolumn{5}{|l|}{ A. Kelompok 1 (Group 1) } \\
\hline $\begin{array}{l}\text { Penibung } \\
\text { (Nibung seeker) }\end{array}$ & 25.000 & 20.000 & 5.000 & 25 \\
\hline $\begin{array}{l}\text { Pemanfaat utama } \\
\text { (Primary beneficiaries ) }\end{array}$ & 40.000 & 25.000 & 15.000 & 75 \\
\hline $\begin{array}{l}\text { Jumlah } \\
\text { (Total) }\end{array}$ & 65.000 & 45.000 & 20.000 & 100 \\
\hline \multicolumn{5}{|l|}{ B. Kelompok 2 (Group 2) } \\
\hline $\begin{array}{l}\text { Penibung } \\
\text { (Nibung seeker) }\end{array}$ & 40.000 & 20.000 & 20.000 & 50 \\
\hline $\begin{array}{l}\text { Pemanfaat utama } \\
\text { (Primary beneficiaries) }\end{array}$ & 60.000 & 40.000 & 20.000 & 50 \\
\hline $\begin{array}{l}\text { Jumlah } \\
\text { (Total) }\end{array}$ & 100.000 & 60.000 & 40.000 & 100 \\
\hline \multicolumn{5}{|l|}{ C. Kelompok 3 (Group 3) } \\
\hline $\begin{array}{l}\text { Penibung } \\
\text { (Nibung seeker) }\end{array}$ & 60.000 & 20.000 & 40.000 & 75 \\
\hline $\begin{array}{l}\text { Pemanfaat utama } \\
\text { (Primary beneficiaries ) }\end{array}$ & 70.000 & 60.000 & 10.000 & 25 \\
\hline $\begin{array}{l}\text { Jumlah } \\
\text { (Total) }\end{array}$ & 130.000 & 80.000 & 50.000 & 100 \\
\hline
\end{tabular}


Dari Tabel 3 diketahui, penibung memiliki input yang sama pada setiap kelompok. Hal ini dikarenakan berapapun panjang batang nibung yang mereka dapatkan, inputnya akan bersifat tetap. Oleh, karena itu, semakin panjang batang nibung yang didapatkan oleh para penibung semakin besar pula nilai tambah yang mereka peroleh karena akan semakin besar output yang mereka peroleh.

\section{KESIMPULAN DAN SARAN}

\section{A. Kesimpulan}

1. Nibung alam yang dimanfaatkan masyarakat dikelompokkan menjadi tiga, yaitu (1) nibung dengan panjang $\leq 12$ meter digunakan sebagai tiang-tiang penyangga rumah panggung, lantai dan jembatan, (2) nibung dengan panjang antara 12-15 meter digunakan sebagai sarip pada kilung dan (3) nibung dengan panjang $>$ 15 meter digunakan untuk membuat bagan.

2. Kebutuhan batang nibung untuk kegiatan pemeliharaan sarana perumahan dan penangkapan ikan pada masyarakat nelayan berdasarkan pendekatan jumlah bangunan yang dimiliki masyarakat pada satu desa adalah sebesar 16.325 btg/tahun. Sedangkan untuk membuat bangunan baru berupa rumah membutuhkan batang nibung sebanyak 100 batang/unit, bagan 200 batang/unit, kilung 1.000 batang/unit, dan toguk 100 batang/unit.

3. Batang nibung tidak dipasarkan secara bebas tetapi berdasarkan pesanan. Pada pemasaran nibung, hanya terdapat 2 (dua) pelaku pemasaran pada setiap kelompok penggunaannya yaitu pemanfaat utama dan penibung. Setiap kelompok pada pemasaran nibung memiliki input yang sama, sehingga besarnya nilai tambah dipengaruhi oleh ukuran panjang batang nibung. Semakin panjang batang nibung yang diperoleh semakin besar pula nilai tambah yang didapatkan.

\section{B. Saran}

1. Untuk mencegah semakin menurunnya potensi nibung dan eksploitasi nibung ke dalam kawasan hutan, perlu adanya kebijakan pemerintah dalam bidang konservasi yang ikut melibatkan masyarakat untuk melakukan kegiatan pembudidayaan nibung.

2. Perlu adanya penelitian lebih lanjut untuk menemukan substitusi nibung agar tidak terjadi over eksploitasi dan alih profesi masyarakat nelayan.

\section{DAFTAR PUSTAKA}

Alamendah. 2011. Pohon Nibung Simbol Persaudaraan Orang Riau. http://alamendah.wordpress. com/2009/12/08/pohon-nibung-simbolpersaudaraan-orang-riau/. Diakses tanggal 25 Juli 2011.

Balai Taman Nasional Sembilang. 2008. Laporan Kegiatan Kajian Identifikasi Peluang Budidaya Nibung oleh Masyarakat. BTN Sembilang. Dirjen Perlindungan Hutan dan Konservasi Alam. Palembang.

Heyne, K. 1987. Tumbuhan Berguna Indonesia Jilid I. Badan Penelitian dan Pengembangan Kehutanan. Departemen Kehutanan. Jakarta.

Kaplinsky, R. and M. Morris. 2000. A Handbook For Value Chain Research. Bellagio Workshop.

Kotler, P. 2002. Manajemen Pemasaran. Edisi Kesepuluh. PT. Prenhalindo. Jakarta.

Limbong, W. H. dan P. Sitorus. 1987. Pengantar Tataniaga Pertanian. Bahan Kuliah Departemen Sosial Ekonomi Pertanian. Institut Pertanian Bogor. Bogor.

Lukman, A. H., H. Siahaan, Sahwalita dan A. Kunarso. 2009. Kajian Sebaran Nibung dan Alternatif Pemanfaatannya Sebagai Bahan Pangan. Laporan Hasil Penelitian. Balai Penelitian Kehutanan Palembang.

Lukman, A. H., H. Siahaan, Sahwalita dan M. Ulfa. 2010. Pengembangan Nibung Sebagai Sumber Pangan dan Kayu Pertukangan. Laporan Hasil Penelitian. Balai Penelitian Kehutanan Palembang.

Martin, E., B. T. Premono dan A. Nurlia. 2010. Pembudidayaan Jenis Gelam Aspek Status Pemanfaatan gelam. Laporan Hasil Penelitian. Balai Penelitian Kehutanan Palembang.

Peraturan Menteri Kehutanan Nomor P.35/MenhutII/2007. Tentang Hasil Hutan Bukan Kayu (HHBK). Departemen Kehutanan. Jakarta.

Rangkuti, N. 2008. Sepucuk Nipah Serumpun Nibung. http://cetak.kompas.com/read/xml. Diakses tanggal 25 Juli 2011.

Sahwalita dan A. B. Hidayat. 2010. Alternatif Budidaya Nibung (Oncosperamae tigillarium (Jade) Ridl.) di Areal Hutan Tanaman Rakyat. Prosiding Seminar Hasil-hasil Penelitian Balai Penelitian Kehutanan Tahun 2009. Pusat Litbang Peningkatan produktivitas Hutan. Badan Penelitian dan Pengembangan Kehutanan. Bogor.

Siahaan, H. dan A.H. Lukman. 2011. Ekologi dan Sebaran nibung (Oncospermae tigillarium (Jack) Ridl) di Sumatera. Prodising Workshop Sintesa Hasil Penelitian Hutan Tanaman 2010. 
Pusat Litbang Peningkatan produktivitas Hutan. Badan Penelitian dan Pengembangan Kehutanan. Bogor.

Shank, J. K. and V. Govindarajan. 1992. Strategic Cost Management and the Value Chain., Thomson Learning.
SPTN II Sembilang. 2009. Kegiatan Pelestarian Nibung Bersama Masyarakat. Laporan Kegiatan. Balai Taman Nasional Sembilang. Dirjen Perlindungan Hutan dan Konservasi Alam. Palembang. 